\title{
CNOP testimony on their understanding of training programs in optics
}

\section{Laétitia Lasagesse}

Laétitia Lasagesse, "CNOP testimony on their understanding of training programs in optics," Proc. SPIE 9664, Ninth International Topical Meeting on Education and Training in Optics and Photonics, 966403 (24 October 2005); doi: $10.1117 / 12.2207696$

Event: Ninth International Topical Meeting on Education and Training in Optics and Photonics, 2005, Marseille, France 
Ref ETOP038

\title{
CNOP testimony on their understanding of training programs in Optics
}

\author{
Laëtitia Lasagesse
}

\section{Abstract}

Within the National Commission for Training in Optics \& Photonics (CNOP), the state of play in education for optics has been compiled at national level from primary \& secondary level to University and technological training levels. Partners from CNOP propose to :

- Present the www.optra.net Website webmastered by Opticsvalley, on which a list of optics training in Europe is available

- Zoom in on Professional diplomas such as CQPM "opticien de précision", CQPM "monteur de précision"

- $\quad$ Present the existing baccalaureat (French A Level) concerning Optics

$-\quad \cdots$

\section{Summary}

The National Commission deals with educational programs in Optics and Photonics in France. This Commission represents

\&\#61692; Regional clusters from :

- $\quad$ lle-de-France (Paris Region): Opticsvalley

- $\quad$ Alsace : Rhénaphotonics

- $\quad$ Provence-Alpes-Côte d'Azur : PopSud

- $\quad$ Bretagne : Anticipa

- $\quad$ Rhône-Alpes : Alpes Optique \& Photonique, Optique \& Vision

\&\#61692; $\quad$ Members from Industry : Essilor, BBGR

\&\#61692; Members from educational organisations : lycée Fresnel, CFA Pierre et Marie Curie, $\ldots$

\&\#61692; Members from the French Optical Society (SFO)

\&\#61692; Representatives from the French optics industry federation : AFOP-GIFO

Thanks to regular meetings and joint projects, the CNOP has developed indepth knowledge of optical training. The state of play of optics education has been compiled, comprising a list of all the existing training programmes in France from primary \& secondary level to University and technological levels. Thanks to European-funded project OPTRA-NET, this information is now available on www.optra.net, a web site managed by Opticsvalley. The Website is a practical tool for students in order to obtain information on training programmes and degrees and to have practical data on the relevant schools. Some specific actions have been undertaken for optics :

- $\quad$ creation in Paris of a professional diploma called "Contrat de qualification professionnel opticien de précision" in order to cater to an industrial need

- creation in St Etienne of a professional diploma called "contrat de qualification professionnel monteur de précision"

- Creation of an optical specialisation within the professional micro-technologies baccalaureat (French A Level)

Cooperation for the creation and the implementation of such diplomas has been very strong between clusters, federations and the National Education Ministry.

The CNOP partners propose to share their cooperating experience by focusing on one or several topics during the ETOP session concerning the state of the art of education. 